University of Nebraska - Lincoln

DigitalCommons@University of Nebraska - Lincoln

2011

Performance of Whipple shields at impact velocities above $9 \mathrm{~km} /$ S

A.J. Piekutowski

University of Dayton Research Institute, ABPiekutowski@msn.com

K.L. Poormon

University of Dayton Research Institute

E.L. Christiansen

NASA Johnson Space Center

B.A. Davis

NASA Johnson Space Center

Follow this and additional works at: https://digitalcommons.unl.edu/nasapub

Part of the Physical Sciences and Mathematics Commons

Piekutowski, A.J.; Poormon, K.L.; Christiansen, E.L.; and Davis, B.A., "Performance of Whipple shields at impact velocities above $9 \mathrm{~km} / \mathrm{s} "$ (2011). NASA Publications. 80.

https://digitalcommons.unl.edu/nasapub/80

This Article is brought to you for free and open access by the National Aeronautics and Space Administration at DigitalCommons@University of Nebraska - Lincoln. It has been accepted for inclusion in NASA Publications by an authorized administrator of DigitalCommons@University of Nebraska - Lincoln. 


\title{
Performance of Whipple shields at impact velocities above $9 \mathrm{~km} / \mathrm{s}$
}

\author{
A.J. Piekutowski ${ }^{a}{ }^{*}$, K.L. Poormon ${ }^{\text {a }}$, E.L. Christiansen ${ }^{\text {b }}$, B.A. Davis ${ }^{b}$ \\ ${ }^{a}$ University of Dayton Research Institute, 300 College Park Avenue, Dayton, OH 45469-0116, USA \\ ${ }^{\mathrm{b}}$ NASA Johnson Space Center, 2101 NASA Parkway, Mail Code SX2, Houston, TX 77058, USA
}

\section{A R T I C L E I N F O}

Article history:

Available online 20 November 2010

\section{Keywords:}

Whipple shield

Ballistic limit curves

Aluminum spheres

Critical particle diameter

Rear wall damage

\begin{abstract}
A B S T R A C $T$
The results of 18 impact tests performed on Whipple shields were compared to the predicted ballistic limits of the shields in the region where the impact velocity of the threatening particle was high enough to produce melting and incipient vaporization of the particle. Ballistic limit equations developed at NASA Johnson Space Center were used to determine nominal failure thresholds for two configurations of allaluminum Whipple shields. In the tests, 2017-T4 aluminum spheres with diameters ranging from 1.40 to $6.35 \mathrm{~mm}$ were used to impact the shields at impact velocities ranging from 6.94 to $9.89 \mathrm{~km} / \mathrm{s}$. Two different aluminum alloys were used for the rear walls of a simple Whipple shield. The results of 13 tests using these simple Whipple shields showed they offered better-than-predicted capability as impact velocity increased and that the strength of the rear wall material appeared to have a smaller-thanpredicted effect on the shield performance. The results of five tests using three configurations of a scaled Space Station shield - a plain shield at 0 degrees, two shields with multilayer insulation in the space between the bumper and the rear wall (also at 0 degrees), and two tests with the plain shield at 45 degrees obliquity - showed that these shields met their predicted capabilities.
\end{abstract}

(c) 2010 Elsevier Ltd. All rights reserved.

\section{Introduction}

Whipple shields were first proposed as a means of protecting spacecraft from the impact of micrometeoroids in 1947 [1] and are currently in use as micrometeoroid and orbital debris shields on modern spacecraft. In the intervening years, the function of the thin bumper used to shatter or melt the threatening particles has been augmented and enhanced by the use of different types and configurations of intermediate layers of various materials. All shield designs serve to minimize the threat of a spall failure or perforation of the main wall of the spacecraft as a result of the impact of the particles.

Various ballistic limit or "failure" equations for guiding the design and estimating the performance of Whipple shield systems have been developed. Most of these equations were developed in the 1960s and are used to estimate the performance of shields designed to provide protection against the extremely high impact velocities of micrometeoroids $(11-72 \mathrm{~km} / \mathrm{s})$.

With the subsequent emergence of orbital debris as a more serious threat to spacecraft shielding, additional relationships were required for predicting the performance of shields impacted by lower velocity particles. Hayashida and Robinson [2] examined

\footnotetext{
* Corresponding author. Tel.: +1 937588 2822; fax: +1 9372293869.

E-mail address: ABPiekutowski@msn.com (A.J. Piekutowski).
}

seven of the more commonly used double-plate penetration equations for their accuracy and effectiveness in the development of shield designs. The best known and most used of the equations they examined is the set of "new" modified Cour-Palais or Christiansen equations [3]. In their examination, this set of equations were the only equations which addressed the three phases of impact: (1) ballistic $(<3 \mathrm{~km} / \mathrm{s})$, where the projectile is moving too slowly to fragment and essentially penetrates as an intact projectile; (2) shatter $(3-7 \mathrm{~km} / \mathrm{s})$, where the projectile fragments at impact and forms an expanding cloud of debris fragments; and (3) melt/vaporization $(>7 \mathrm{~km} / \mathrm{s})$, where the projectile melts or vaporizes at impact.

The results of 18 hypervelocity impact tests are presented in this paper. Thirteen test firings were made using three scales of a simple Whipple shield as targets and five test firings were made using a one-third-scale version of an all-aluminum Whipple shield installed on the U.S. Laboratory Module of Space Station as targets. The result of each test firing was compared to the appropriate ballistic limit curve generated for each of the shield designs. Six test firings, with impact velocities ranging from 6.94 to $7.28 \mathrm{~km} / \mathrm{s}$, were made using a two-stage, light-gas gun and 12 test firings, with impact velocities ranging from 8.75 to $9.89 \mathrm{~km} / \mathrm{s}$, were made using a three-stage, light-gas gun recently developed at the University of Dayton Research Institute (UDRI) [4]. The initial objective during the development of the UDRI, three-stage, light-gas gun was to launch 2.4-mm-diameter aluminum spheres to velocities of at least 
$9 \mathrm{~km} / \mathrm{s}$. Expanding the range of projectile diameters and increasing impact velocities were the objectives of later work. The ultimate objective was the development of a light-gas gun capable of launching aluminum spheres to ultra-high velocities in order to extend the upper velocity limits of existing collections of impact data generated using aluminum spheres as projectiles.

\section{Simple, all-aluminum Whipple shield design}

The simple Whipple shield used in the initial test firings and for later work was a scaled version of a shield presented fairly frequently in publications made during the development of shielding designed for use on portions of Space Station. This shield consisted of a 1.27-mm-thick, 6061-T6 aluminum bumper and a 3.18-mm-thick, 2219-T87 aluminum rear wall. Spacing between the bumper and the rear wall was $10.2 \mathrm{~cm}$. Ballistic limit curves presented for this shield in Ref. [3] indicated that the critical aluminum particle diameter for a normal impact at a velocity of $9 \mathrm{~km} / \mathrm{s}$ was $0.479 \mathrm{~cm}$, or twice the diameter of the 2.4 -mm-diameter aluminum sphere used in the initial three-stage gun test firings.

A test firing using a 2.4-mm-diameter projectile, an impact velocity of $9 \mathrm{~km} / \mathrm{s}$, and a shield which was slightly less than half scale would produce a data point that was above the ballistic limit curve, where a pass or a fail would provide useful information for validating the predicted performance of the shield. An appropriate thickness of 2219-T87 aluminum sheet suitable for use as the rear wall of the reduced scale shield was not available. Consequently, 1.463-mmthick sheets of 6061-T6 aluminum were substituted and used for rear walls for the initial test firings. Later, pieces of 2219-T87 aluminum sheet were machined to provide $1.463-\mathrm{mm}$-thick rear walls for use in other test firings. The ratio of the thickness of the scaled and full-scale rear walls $(1.463 \mathrm{~mm} \div 3.175 \mathrm{~mm}=0.4608)$ was used as the scaling factor for the remainder of the shield design. This scaled shield is referred to as the 0.46 -scale shield in the rest of the paper. The nominal 0.46 -scale shield bumper thickness was $0.585 \mathrm{~mm}$; the closest thickness of 6061-T6 aluminum sheet available and used as bumpers for the 0.46-scale simple shields was $0.597 \mathrm{~mm}$. Spacing of the bumper and the rear wall for the 0.46 -scale shield was $4.699 \mathrm{~cm}$.

As the examination of the ballistic limit performance equations for the 0.46-scale shields progressed for impact velocities near $9 \mathrm{~km} / \mathrm{s}$, interest in the adequacy of the equations for impact velocities below and above $9 \mathrm{~km} / \mathrm{s}$ developed. Consequently, the results of three full-scale shield tests performed in 1992 were included in the examination. These tests, performed for Boeing Defense \& Space Group, used 5.96-mm- and 6.35-mm-diameter, 2017-T4 aluminum spheres and impact velocities of 6.94, 7.09, and $7.19 \mathrm{~km} / \mathrm{s}$. Three two-stage, light-gas gun test firings were also performed using the 0.46 -scale shields, spheres with appropriately scaled diameters, and impact velocities near $7 \mathrm{~km} / \mathrm{s}$ to: (1) provide additional performance data; (2) compare 0.46 -scale shield damage to full-scale shield damage; and (3) "validate" the scaling technique used in the design of the 0.46-scale shield.
Test firings performed using the UDRI three-stage, light-gas gun at velocities greater than $9.3 \mathrm{~km} / \mathrm{s}$ required the diameter (and mass) of the aluminum spheres be reduced in order to achieve higher launch velocities. Therefore, the scale of the simple Whipple shields used as targets for these higher velocity test firings was reduced to a nominal $0.25 / 0.26$ scale using the procedures followed during the design of the 0.46-scale shield. Although the actual scale of the two shields used for the test firings at the higher velocities are different, they will be referred to as 0.25 -scale shields.

A summary of the dimensions of the bumpers, rear walls, and the spacing between the sheets is presented in Table 1 for the various scales of the simple Whipple shield and the one-third-scale Space Station shield evaluated in this test series.

A comment regarding the scaling of the shields is in order. Because of rate effects, some properties of the scaled targets do not scale. For example, the length of the zone of projectile and target material which is responding to the transient impact-induced stresses and strains does not change as the target scale changes. As a result, more of the energy available from the impacting projectile is consumed by this process as the projectile and shield scale decreases, making the smaller-scale shields appear "harder" and larger-scale shields appear "softer." This effect on shield resistance to failure must be considered when comparing the results of tests performed using targets with different scale factors.

\section{Aluminum Whipple shield ballistic limit equations}

Reference [3] provides a number of design and performance equations for advanced meteoroid and orbital debris shields. Design of a shield is usually an iterative process in which: (1) a shield design is selected; (2) its performance is evaluated using ballistic limit equations; ( 3 ) the shield design is modified because the initial design failed to meet operational requirements; (4) the performance of the modified design is re-evaluated; and (5) the cycle is repeated as necessary. Design equations presented by Christiansen have two parts: (1) design or sizing equations used to determine the preliminary shielding thicknesses and weights and (2) performance or "ballistic limit" equations used to determine the maximum protection capability of the shield. Because the dimensions and properties of the shields which were used for the test firings described in this paper were defined, only the performance equations used to determine the adequacy of the aluminum Whipple shields are presented.

The following equations are used to define the ballistic limits for an all-aluminum Whipple shield in terms of the critical particle diameter, $d_{c}$. The applicable velocity range for each equation is specified in terms of $V_{\mathrm{n}}$, the normal component of the projectile velocity for cases in which the projectile impacts at an oblique angle. The critical particle diameter when $V_{\mathrm{n}} \leq 3 \mathrm{~km} / \mathrm{s}$ is given as follows:

$d_{\mathrm{c}}=\left[\left(t_{\mathrm{w}}(\sigma / 40)^{0.5}+t_{\mathrm{b}}\right) /\left(0.6(\cos \theta)^{5 / 3} \rho_{\mathrm{p}}^{0.5} V^{2 / 3}\right)\right]^{(18 / 19)}$

Table 1

Dimensions of various Whipple shield components.

\begin{tabular}{|c|c|c|c|}
\hline Shield & Bumper & Spacing & Rear wall \\
\hline Full-scale simple & $0.0505 \times 6 \times 6$ in. $6061-\mathrm{T} 6 \mathrm{Al}(0.1283 \times 15.2 \times 15.2 \mathrm{~cm})$ & $4.00 \mathrm{in} .(10.160 \mathrm{~cm})$ & $0.126 \times 16 \times 16$ in. $2219-\mathrm{T} 87 \mathrm{Al}(0.320 \times 40.6 \times 40.6 \mathrm{~cm})$ \\
\hline 0.46-scale simple & $0.0235 \times 3 \times 3$ in. $6061-\mathrm{T} 6 \mathrm{Al}(0.0597 \times 7.6 \times 7.6 \mathrm{~cm})$ & 1.85 in. $(4.669 \mathrm{~cm})$ & $0.0576 \times 6 \times 6$ in. $6061-\mathrm{T}^{2} \mathrm{Al}^{\mathrm{a}}(0.1463 \times 15.2 \times 15.2 \mathrm{~cm})$ \\
\hline 0.25-scale simple & $0.0125 \times 4 \times 4$ in. $6061-\mathrm{T} 6 \mathrm{Al}(0.0318 \times 10.2 \times 10.2 \mathrm{~cm})$ & $1.00 \mathrm{in}(2.540 \mathrm{~cm})$ & $0.0317 \times 4 \times 4$ in. $2219-\mathrm{T} 87 \mathrm{Al}(0.0805 \times 10.2 \times 10.2 \mathrm{~cm})$ \\
\hline 0.26-scale simple & $0.0131 \times 4 \times 4$ in $6061-\mathrm{T} 6 \mathrm{Al}(0.0333 \times 10.2 \times 10.2 \mathrm{~cm})$ & 1.04 in. $(2.642 \mathrm{~cm}$ & $0.0325 \times 4 \times 4$ in. $6061-\mathrm{T} 6 \mathrm{Al}(0.0826 \times 10.2 \times 10.2 \mathrm{~cm})$ \\
\hline 1/3-scale space station & $0.025 \times 6 \times 6$ in. $6061-\mathrm{T} 6 \mathrm{Al}(0.0635 \times 15.2 \times 15.2 \mathrm{~cm})$ & 1.40 in. $(3.556 \mathrm{~cm})$ & $0.063 \times 6 \times 6$ in. $2024-\mathrm{T} 3 \mathrm{Al}(0.1600 \times 15.2 \times 15.2 \mathrm{~cm})$ \\
\hline
\end{tabular}

a 2219-T87 aluminum rear walls with the same dimensions were also used for the 0.46-scale shields. 
Table 2

Material properties of various aluminum alloys used in impact tests.

\begin{tabular}{lllll}
\hline Material & 2017-T4 & 2024-T3 & 2219-T87 & 6061-T6 \\
\hline Density, g/cm & 2.795 & 2.780 & 2.840 & 2.702 \\
Yield stress, ksi & 40 & 50 & 57 & 40 \\
\hline
\end{tabular}

For $3 \mathrm{~km} / \mathrm{s}<V_{\mathrm{n}}<7 \mathrm{~km} / \mathrm{s}$ :

$$
\begin{aligned}
d_{\mathrm{c}}= & \left\{\left[\left(t_{\mathrm{w}}(\sigma / 40)^{0.5}+t_{\mathrm{b}}\right) /\left(1.248 \rho_{\mathrm{p}}^{0.5} \cos \theta\right)\right]^{(18 / 19)}\right. \\
& (1.75-(V \cos \theta) / 4)\}+\left\{\left[1.071 t_{\mathrm{w}}^{2 / 3} \rho_{\mathrm{p}}^{-1 / 3} \rho_{\mathrm{b}}^{-1 / 9} S^{1 / 3}(\sigma / 70)^{1 / 3}\right]\right. \\
& ((V \cos \theta) / 4-0.75)\}
\end{aligned}
$$

For $V_{\mathrm{n}}>7 \mathrm{~km} / \mathrm{s}$ :

$d_{\mathrm{c}}=3.918 t_{\mathrm{w}}^{2 / 3} \rho_{\mathrm{p}}^{-1 / 3} \rho_{\mathrm{b}}^{-1 / 9}(V \cos \theta)^{-2 / 3} S^{1 / 3}(\sigma / 70)^{1 / 3}$

Eqs. (2) and (3) were used with the material properties given in Table 2 and the dimensions of the 0.46-scale simple Whipple shield and the one-third-scale Space Station shield to determine the various ballistic limit curves presented later in this paper.

These three equations are used to define the critical particle diameter, $d_{c}$ (given in $\mathrm{cm}$ ), which causes failure of the shield at the impact velocity of interest. Failure of the shield is defined as a: (1) perforation of the rear wall or (2) loss of material (detached spall) from the rear surface of the rear wall. An attached spall blister with cracking but no loss of material is considered a pass. In the ballistic limit equations, bumper thickness, rear wall thickness, and sheet spacing are denoted as $t_{\mathrm{b}}, t_{\mathrm{w}}$, and $S$, respectively, and are measured in $\mathrm{cm}$. Impact velocity, $V$, is given in units of $\mathrm{km} / \mathrm{s}$. The densities of the bumper and projectile, $\rho_{\mathrm{b}}$ and $\rho_{\mathrm{p}}$, respectively, are given in units of $\mathrm{g} / \mathrm{cm}^{3}$. The rear wall yield stress, $\sigma$, is given in the English units of ksi. The impact angle, $\theta$, is the angle the shot-line axis makes with the shield surface normal and is given in degrees. Eq. (3) applies when the ratio, $S / d$, where $d$ is the particle diameter, is greater than 15 for aluminum-on-aluminum impacts or the ratio $\left(t_{\mathrm{b}} \rho_{\mathrm{b}}\right) /\left(d \rho_{\mathrm{p}}\right)$ is greater than 0.18 for normal impacts. All of the Whipple shields described in Table 1 meet these criteria.

\section{Experimental procedures}

All impact tests were performed in the UDRI Impact Physics Laboratory using a 50/20 mm, two-stage, light-gas gun and a 75/30/ $7.62 \mathrm{~mm}$, three-stage light-gas gun. The third stage of this gun, which consisted of a high-pressure section and a 7.62-mm-bore launch tube, was attached to the muzzle of the UDRI $75 / 30 \mathrm{~mm}$, two-stage, light-gas gun and used to launch the smaller projectiles. The UDRI three-stage, light-gas gun has also been used to evaluate the response of various thermal protection system and spacecraftrelated materials to the impact of aluminum and Nylon projectiles at ultra-high velocities.

The Whipple shield targets were installed and impacted with the bumpers and rear walls normal to the range shot line $(\theta=0$ degrees) for all but two of the test firings in which the targets were installed at a 45-degree angle to the shot-line axis. The 0.46-scale bumpers were securely taped to a $15.2-\mathrm{cm}$-square aluminum frame which had a 5.08-cm-square opening cut in its center. The 0.318- and 0.333-mm-thick bumpers were formed by machining a 1.9-cm-diameter section of reduced thickness at the center of a 0.76 -mm-thick sheet of stock. The 0.46 -scale and 0.25 -scale 2219-T87 aluminum rear walls were machined from $1.57-\mathrm{mm}$ thick sheet stock to bring them to the correct thickness. After machining, the thinned bumpers and rear walls were polished to remove tool marks and were installed with the polished surfaces facing the gun. The full-scale shield bumpers were held at their corners by screws which passed through the sheets into appropriate support posts in the target chamber. Bumpers and rear wall spacing for the other Whipple shields was maintained by using spacers of the correct length between the sheets and threaded rods or screws passing through the corners of the sheets/frames to hold them in place. The atmosphere in the target chamber was air at a pressure of 5-12 $\mathrm{mm} \mathrm{Hg}$ for the two-stage gun and $6 \mathrm{~mm} \mathrm{Hg}$ for the three-stage gun.

Projectiles used for the test firings were 2017-T4 aluminum spheres with diameters ranging from $1.40 \mathrm{~mm}$ to $6.35 \mathrm{~mm}$. Projectile integrity was verified using orthogonal, flash X-ray views of the projectile in flight. These views were taken after the sabot had been stripped and just before impact using Field Emission $180 \mathrm{kV}$, dual-head, flash X-ray systems with orthogonal pairs of Scandiflash $150 \mathrm{kV}$ remote tube heads. The tube heads were fitted

Table 3

\begin{tabular}{|c|c|c|c|c|c|c|}
\hline \multirow{2}{*}{$\begin{array}{l}\text { UDRI Shot } \\
\text { No. }\end{array}$} & \multicolumn{2}{|l|}{ Projectile } & \multirow{2}{*}{$\begin{array}{l}\text { Rear wall alloy and } \\
\text { thickness, inches }\end{array}$} & \multirow{2}{*}{$\begin{array}{l}\text { Impact } \\
\text { velocity, } \\
\mathrm{km} / \mathrm{s}\end{array}$} & \multicolumn{2}{|c|}{ Post-test condition of rear wall } \\
\hline & $\begin{array}{l}\text { Diameter, inches } \\
(\mathrm{cm})\end{array}$ & Mass, $g$ & & & Pass/fail & Description of damage exhibited on rear surface \\
\hline \multicolumn{7}{|c|}{ Full-scale tests } \\
\hline $4-1415$ & $0.2498(0.6345)$ & 0.3729 & 2219-T87 Al 0.1260 & 7.19 & Fail & 0.70 in. $\times 0.72$ in. $(0.32$ in. $\times 0.33$ in. scaled $)$ through hole \\
\hline 4-1416 & $0.2348(0.5964)$ & 0.3095 & 2219-T87 Al 0.1260 & 7.09 & Fail & 1.22-in.-dia. (0.56-in.-dia. scaled) detached spall \\
\hline 4-1417 & $0.2348(0.5964)$ & 0.3096 & 2219-T87 Al 0.1260 & 6.94 & Fail & 1.24 in. $\times 1.30$ in. ( 0.57 in. $\times 0.60$ in. scaled $)$ detached spall \\
\hline \multicolumn{7}{|c|}{0.46 -Scale tests } \\
\hline $4-2011$ & $0.1021(0.2593)$ & 0.0253 & 2219-T87 Al 0.0583 & 7.25 & Pass & 0.59-in.-dia. spall ring and 0.22-in.-dia. central blister \\
\hline 4-2012 & $0.1068(0.2713)$ & 0.0288 & 2219-T87 Al 0.0584 & 7.09 & Pass & 0.59-in.-dia. central spall with several open cracks at edges \\
\hline $8-3260$ & $0.0938(0.2383)$ & 0.0196 & 2219-T87 Al 0.0583 & 9.03 & Pass & Slight bulge, 0.12 -in.-dia. central blister and partial spall ring \\
\hline $8-3288$ & $0.1024(0.2601)$ & 0.0254 & 2219-T87 Al 0.0577 & 9.29 & Fail & Bulging with a 0.12 in. $\times 0.14$ in. spall and partial spall ring \\
\hline 4-2010 & $0.1024(0.2601)$ & 0.0253 & 6061-T6 Al 0.0576 & 7.28 & Pass & 0.21 in. $\times 0.23$ in. blister with open crack, 0.56 -in.-dia spall ring \\
\hline $8-3212$ & $0.0938(0.2383)$ & 0.0197 & 6061-T6 Al 0.0576 & 8.75 & Pass & Slight bulging, with several small blisters \\
\hline $8-3217$ & $0.0928(0.2357)$ & 0.0193 & 6061-T6 Al 0.0576 & 9.07 & Pass & Slight bulging, with several small blisters \\
\hline $8-3224$ & $0.1022(0.2596)$ & 0.0253 & 6061-T6 Al 0.0576 & 8.97 & Fail & Some bulging with a 0.16 -in.-dia. detached spall, partial spall ring \\
\hline \multicolumn{7}{|c|}{0.25 -Scale tests } \\
\hline $8-3291$ & $0.0565(0.1435)$ & 0.0045 & 2219-T87 Al 0.0317 & 9.72 & Pass & Bulge with a 0.16-in.-dia. central blister with large open cracks \\
\hline $8-3292$ & $0.0551(0.1400)$ & 0.0041 & 6061-T6 Al 0.0325 & 9.89 & Pass & Bulge with a 0.24-in.-dia. central blister ${ }^{\mathrm{a}}$ with large open cracks \\
\hline
\end{tabular}

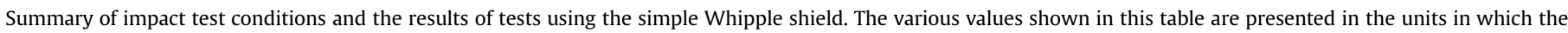
properties were measured.

\footnotetext{
a Several small stripper-plate fragments struck the rear wall and exaggerated the size of the spall blister.
} 


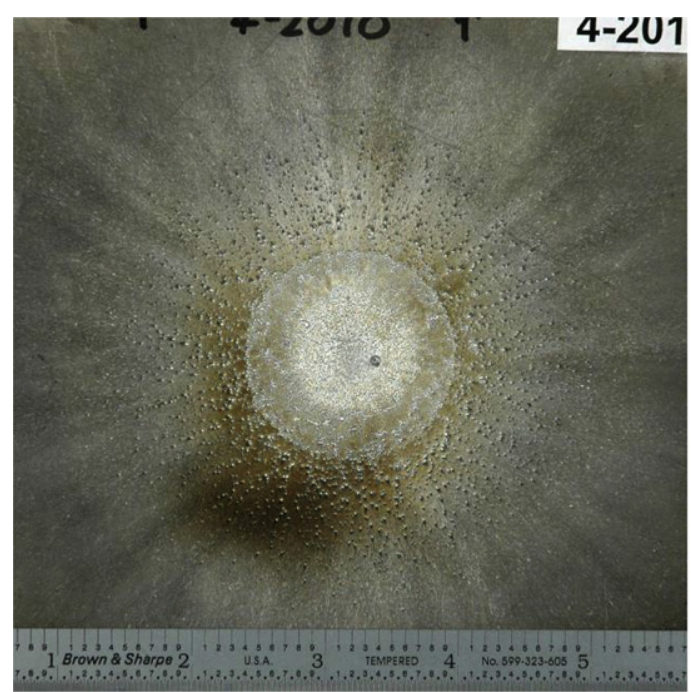

2.60-mm-dia., 2017-T4 Al sphere at $7.28 \mathrm{~km} / \mathrm{s}$ Shot No. 4-2010

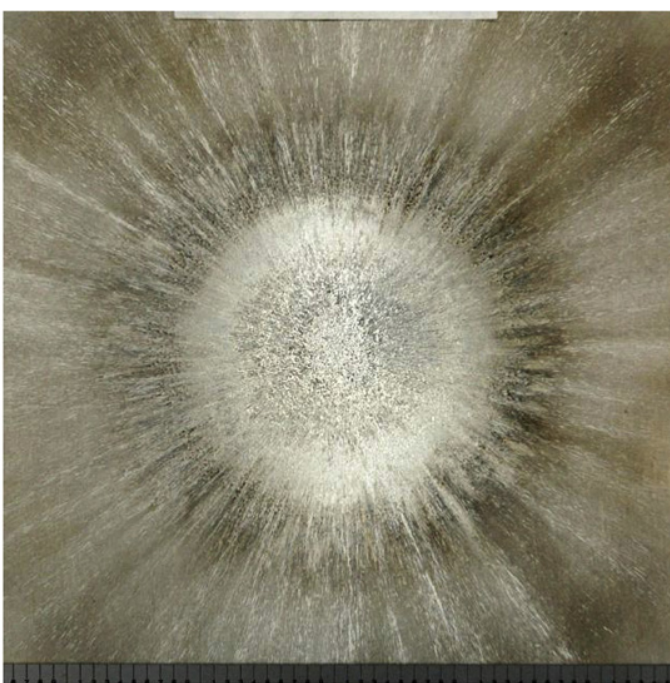

2.60-mm-dia., 2017-T4 Al sphere at $9.29 \mathrm{~km} / \mathrm{s}$ Shot No. 8-3288

Fig. 1. Views of the damage patterns produced on the front surfaces of the rear walls of two, 0.46 -scale Whipple shields.

with windows which allowed passage of the "soft" portion of the spectrum of radiation emitted by the tube heads to maximize the sensitivity of the radiographic film to the small quantities aluminum used for the spheres. Radiographs were made using Kodak BioMax MS film in a direct-exposure mode.

Impact velocity determinations were made with use of four laser-photodetector stations for the two-stage gun and three laserphotodetector stations for the three-stage gun. These laser-photodetector systems were installed at various locations along the flight path of the projectile. Projectile velocities were computed by dividing the distance between pairs of stations by the corresponding time of flight of the projectile between those stations. The accuracy of the impact velocity determinations was better than $\pm 0.5 \%$ for the two-stage gun and $\pm 0.16 \%$ for the three-stage gun.

\section{Results and discussion}

A summary of the impact test conditions and the results of the 13 tests which used the three scales of the simple Whipple shield are presented in Table 3. Views of the damage patterns produced on the front surfaces of the rear walls for two 0.46-scale shields are shown in Fig. 1. These patterns clearly illustrate the effect a change in the state of the material in the debris clouds has on the damage patterns produced by the impacts. The damage pattern on the rear

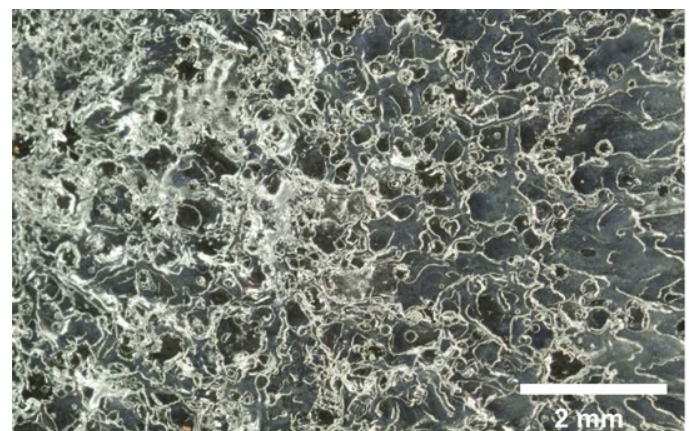

a

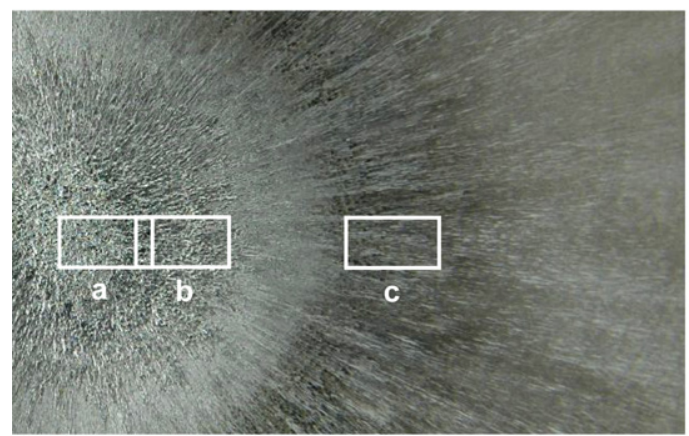

Location of views (a), (b), and (c)

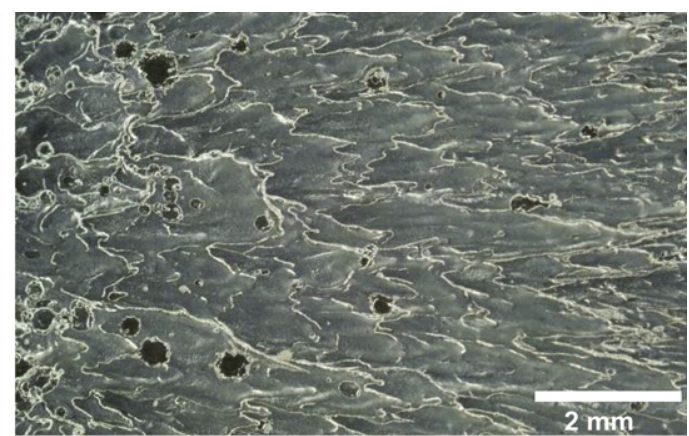

b

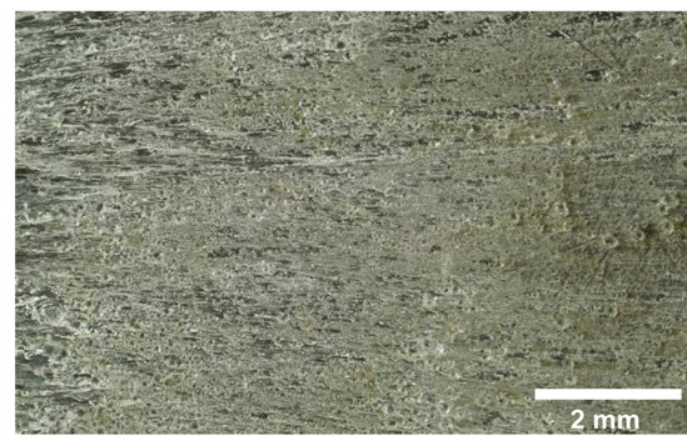

C

Fig. 2. Views of sections of damage pattern formed on front surface of rear wall for test at $9.29 \mathrm{~km} / \mathrm{s}$ (Shot No. 8-3288). 


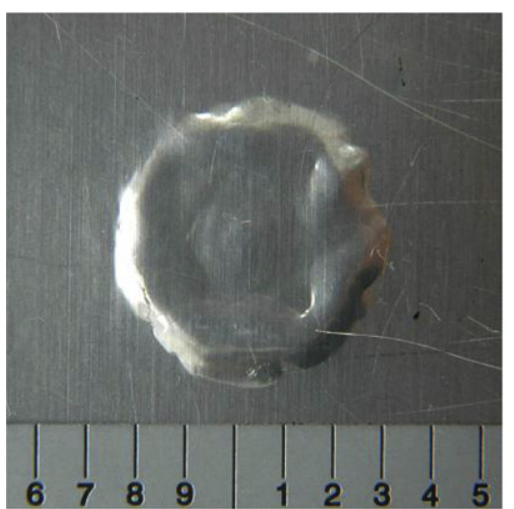

$7.09 \mathrm{~km} / \mathrm{s}$ (Pass)

Shot No. 4-2012

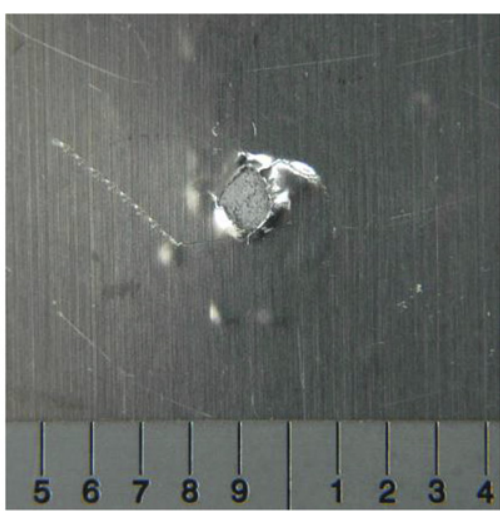

$9.29 \mathrm{~km} / \mathrm{s}$ (Fail)

Shot No. 8-3288

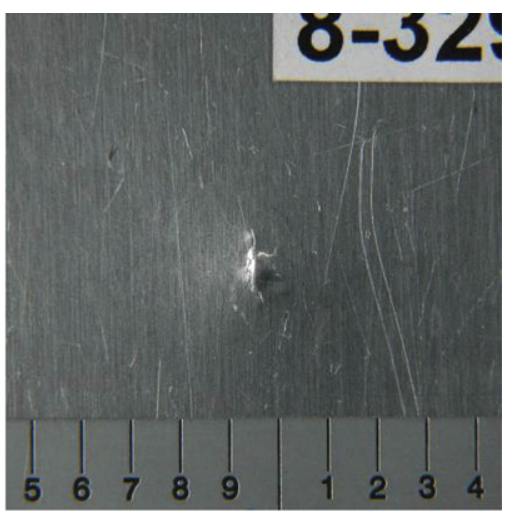

$9.72 \mathrm{~km} / \mathrm{s}$ (Pass)

Shot No. 8-3291

Fig. 3. Views of damage to rear surface of 2219-T87 aluminum rear walls for tests near the failure threshold (scales in inches).

wall of the shield used for the $7.28 \mathrm{~km} / \mathrm{s}$ test exhibited a very clear boundary between craters formed by the impact of solid projectile fragments (inside the circular boundary) and solid bumper fragments (outside the boundary). Some melting of the rear wall surface is evident in a small region at the center of the pattern. The damage pattern on the rear wall from the $9.29 \mathrm{~km} / \mathrm{s}$ test has several concentric and roughly circular regions which exhibit different textures. Also evident on the surface of this rear wall are numerous "rays" or tracks left by droplets of molten aluminum as they flowed away from the center of the rear wall.

The debris cloud formed by the normal impact of an aluminum sphere with an aluminum bumper at an impact velocity $\geq 9 \mathrm{~km} / \mathrm{s}$ produces a damage pattern which exhibits an abundance of molten aluminum on the rear wall of the shield. Examination of this surface using a microscope reveals at least three distinct regions, shown in Fig. 2, which make up the damage pattern. The surfaces of the regions shown in Fig. 2(a) and (b) are covered with molten aluminum; the region shown in Fig. 2(c) is not.

Features of the region shown in Fig. 2(a) may indicate that debris cloud material striking this area of the rear wall was traveling along a trajectory which was nearly normal to the rear wall surface. The irregularly shaped "craters" tend toward more circular shapes and the overlapping pattern of multiple impacts would indicate that their formation took place over some period of time.

The region shown in Fig. 2(b) exhibits few "craters" and a very pronounced flow pattern indicating that significant amounts of molten sphere, bumper, and rear wall material flowed along a radial path away from the center of impact of the debris cloud. An interesting feature of this flow pattern is the apparent direction of the "shingling" of the frozen material in this region. "Tongues" of molten material at the outer limits of the flow pattern appear to have been laid down first, with the material closest to the center of impact being laid down last.

The section of rear wall shown in Fig. 2(c) lies outside the region exhibiting significant amounts of molten material. Small impact craters evident in this region were undoubtedly formed by the impact of solid bumper fragments. Frequently, the lips of these craters diverted the flow of molten material which arrived after the craters were formed. This region also contained many "tracks" formed by the movement of molten material along the surface of the rear wall. In some cases, usually for impact velocities below $9 \mathrm{~km} / \mathrm{s}$, the molten material which formed these tracks froze on the rear wall. The end of the elongated droplet closer to the center of the pattern peeled away from the rear wall and curled up, giving the rear wall the appearance of having "whiskers." Rear walls from shields impacted at higher velocities did not usually exhibit these "whiskers," apparently because the droplets were hotter, traveling at higher velocities, and moved off the surface of the rear wall before they could solidify.

Thus far, there has not been an attempt to obtain flash radiographs of the debris clouds produced by the test firings. The size and close spacing of the bumper and rear wall require that the placement of the film would be too far away from the debris cloud to obtain a quality image. However, radiographs of molten and

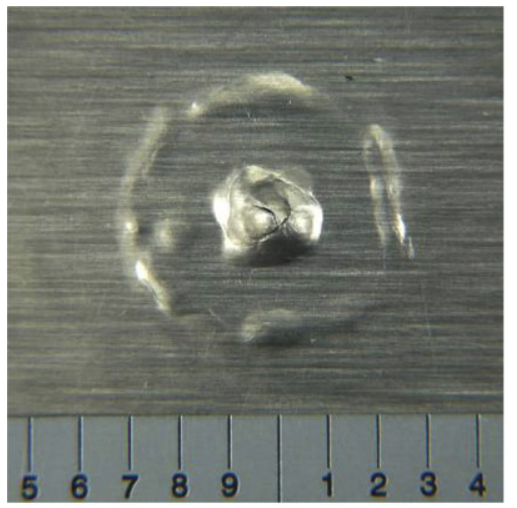

$7.28 \mathrm{~km} / \mathrm{s}$ (Pass)

Shot No. 4-2010

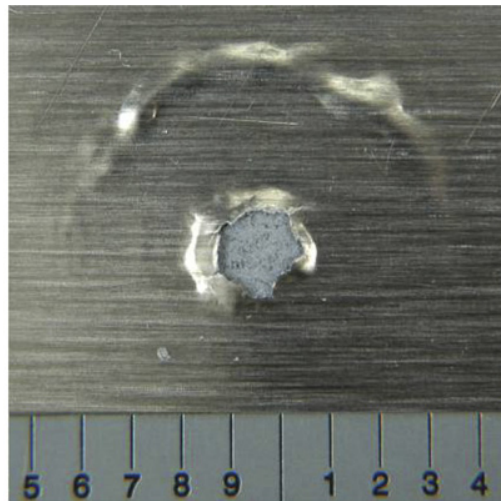

$8.97 \mathrm{~km} / \mathrm{s}$ (Fail)

Shot No. 8-3224

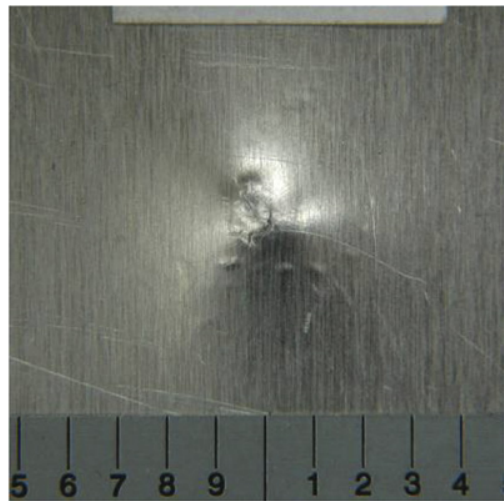

$9.89 \mathrm{~km} / \mathrm{s}$ (Pass)

Shot No. 8-3292

Fig. 4. Views of damage to rear surface of 6061-T6 aluminum rear walls for tests near the failure threshold (scales in inches). 


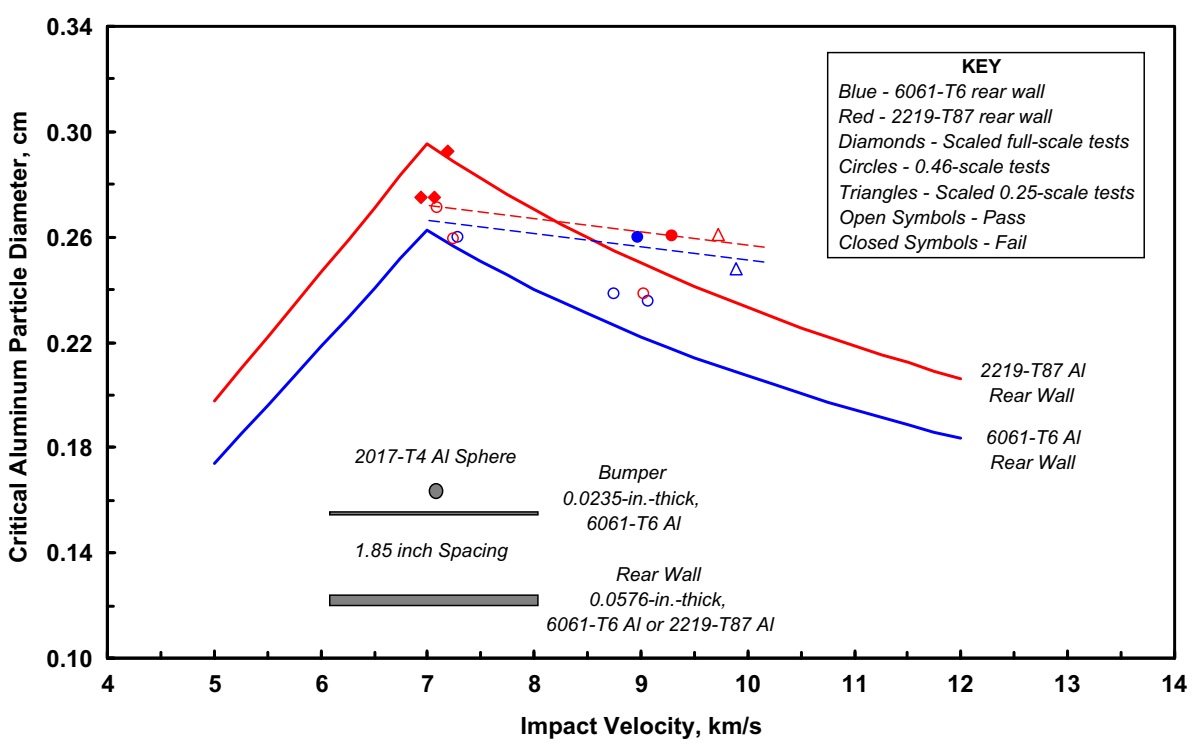

Fig. 5. Ballistic limit curves and test data for impact tests performed using the simple Whipple shield.

vaporous debris clouds formed by the impact of cadmium spheres with cadmium bumpers were presented and described in Ref. [5]. It is likely that the internal structures of the higher velocity, all-aluminum debris clouds formed by the test firings described in this paper are identical to the internal structures of the molten and vaporous cadmium debris clouds. The molten sphere and bumper material forming the internal structure of these debris clouds occupies an oblate-shaped volume. As a result, the material at the center of the trailing edge of this internal structure is the last to impact the rear wall and would strike the rear wall at the center of the damage pattern. In addition to an axial velocity, most material in the debris cloud has a radial velocity component whose magnitude increases as the distance from the axis of the internal structure increases. Deposition of molten sphere material with this combination of axial and radial velocity components would likely produce the central cratered region and the shingled pattern shown in Fig. 2(a) and (b).

The damage produced on the rear surface of a rear wall is critical to an assessment of the performance of the shield. Views of the damage produced on the rear surfaces of three, 2219-T87 aluminum and three, 6061-T6 aluminum rear walls are shown in Figs. 3 and 4, respectively. The rear walls for the two lower velocity tests in each figure are 0.46-scale; the rear walls for the highest velocity test shown in each figure are 0.25 -scale. Recalling the definition of a shield failure - penetration or loss of rear wall material - only the rear wall in the center of each figure failed. The damage shown on the rear wall from Shot No. 4-2012 is extensive. The spall blister is about to come off and exhibits several cracks but no loss of rear wall material. As noted in Table 3, the diameter of this blister is $\sim 0.75 \mathrm{~mm}$ larger than the scaled diameter of the detached spall noted for the full-scale test, Shot No. 4-1416, which had the same impact velocity and used a sphere which was $0.035 \mathrm{~mm}$ larger when scaled. Detached spalls on the rear walls for Shot Nos. 8-3288 and 8-3224 indicate obvious failures. The rear wall for Shot No. 8-3291 did not fail but the bulge and cracked central blister indicated that the test conditions were approaching those required to produce a rear wall failure. Damage observed on the rear walls shown in Fig. 4 is essentially the same as the damage observed on the rear walls shown in Fig. 3.

Performance data for all tests using the simple Whipple shield are compared to the appropriate ballistic limit curves in Fig. 5. The ballistic limit curves shown in Fig. 5 were generated using Eqs. (2) and (3) and the appropriate shield dimensions and material property data. The sphere diameters shown in Fig. 5 were taken directly from the test data for the 0.46 -scale shields. Sphere diameters for the three full-scale tests were normalized to 0.46-scale test diameters by multiplying them by the scale factor, 0.4608 . Sphere diameters for the two 0.25 -scale tests were normalized by multiplying them by the ratio of the scale factor 0.4608 divided by the actual scale of each 0.25 -scale shield.

Straight lines are drawn through the two sets of three data points obtained from the tests shown in Figs. 3 and 4. The line drawn through the data for the tests using the 2219-T87 rear walls should actually curve upward in order to get the "Passes" and the "Fails" on the correct sides of the line. The fact that the machined 2219-T87 aluminum rear wall for the 0.25-scale shield was a little

Table 4

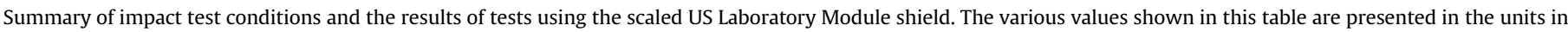
which the properties were measured.

\begin{tabular}{|c|c|c|c|c|c|c|}
\hline \multirow{2}{*}{$\begin{array}{l}\text { UDRI Shot } \\
\text { No. }\end{array}$} & \multicolumn{2}{|l|}{ Projectile } & \multirow[t]{2}{*}{ Target configuration } & \multirow{2}{*}{$\begin{array}{l}\text { Impact } \\
\text { velocity, } \\
\mathrm{km} / \mathrm{s}\end{array}$} & \multicolumn{2}{|c|}{ Post-test condition of rear wall } \\
\hline & $\begin{array}{l}\text { Diameter, inches } \\
(\mathrm{cm})\end{array}$ & Mass, $\mathrm{g}$ & & & Pass/Fail & Description of damage exhibited on rear surface \\
\hline $8-3220$ & $0.0938(0.2382)$ & 0.0196 & Plain shield at 0 -degree obliquity & 9.28 & Fail & 0.06-in.-dia detached spall at center of 0.21 -in.-dia. blister \\
\hline $8-3225$ & $0.1022(0.2591)$ & 0.0255 & With MLI at 0-degree obliquity & 8.91 & Fail & 1.8-mm-high bulge and 0.04-in.-dia. through hole \\
\hline $8-3261$ & $0.0938(0.2382)$ & 0.0196 & With MLI at 0 -degree obliquity & 9.20 & Pass & Two moderate and several small blisters \\
\hline $8-3239$ & $0.1023(0.2598)$ & 0.0253 & Plain shield at 45 -degree obliquity & 8.83 & Fail & 0.03 -in.dia. through hole and $0.35 \mathrm{in} . \times 0.40$ in. detached spall \\
\hline $8-3264$ & $0.0938(0.2382)$ & 0.0196 & Plain shield at 45 -degree obliquity & 9.16 & Pass & Large blister near center with small crack $\sim 2.5 \mathrm{~mm}$ long \\
\hline
\end{tabular}




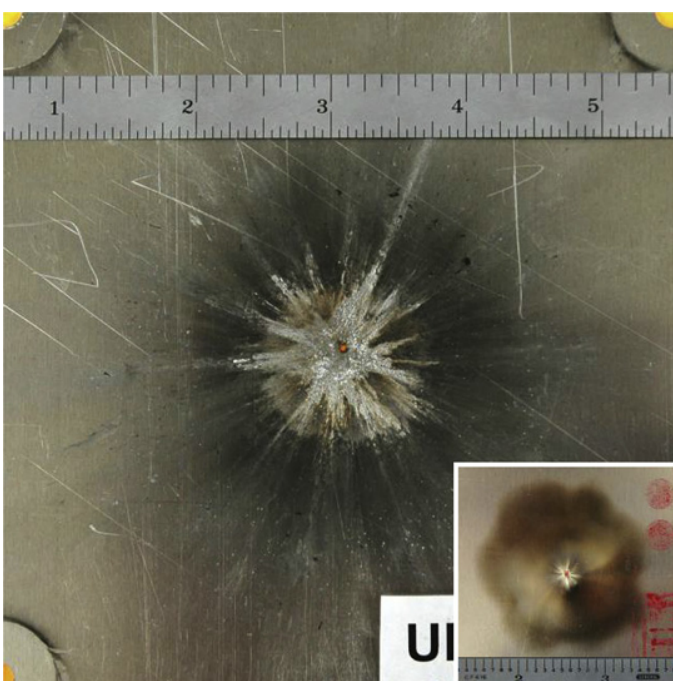

2.59-mm-dia., 2017-T4 Al sphere at $8.91 \mathrm{~km} / \mathrm{s}$ Shot No. 8-3225

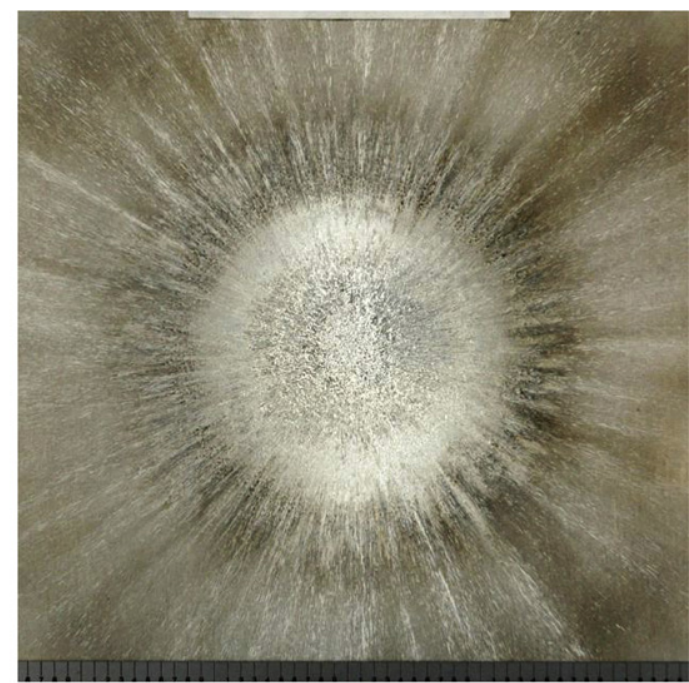

2.60-mm-dia., 2017-T4 Al sphere at $9.29 \mathrm{~km} / \mathrm{s}$ Shot No. 8-3288

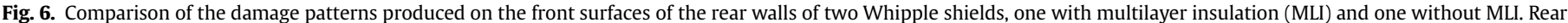
surface of rear wall with MLI is shown in inset (scales in inches).

thicker than the nominal thickness and the likelihood that the shield using this rear wall was a little "harder," because of nonscalable rate effects, could explain why this shield did not fail. Certainly, the boundary between a "Pass" and a "Fail" is not as definitive as the computations which create it and determination of proper shield performance curves for both rear wall materials will require additional testing.

Two notable trends are indicated by the straight lines shown in Fig. 5 for both shield designs. First, while shield performance "falls off" with increasing impact velocity, the rate at which it declines is significantly less than the rate indicated by the ballistic limit curves for each type of rear wall material. Second, differences in the material properties of the rear wall do not appear to have as great an effect on the overall performance of the shield as is predicted by the ballistic limit equations. These observations are based on a very limited dataset and should be reinforced by additional test data obtained in the velocity range examined in this paper and in the range between 7.3 and $8.8 \mathrm{~km} / \mathrm{s}$.

A summary of the impact test conditions and the results of five tests which used the one-third-scale version of the shielding used on the U.S. Laboratory Module of Space Station are presented in Table 4. The five-scaled shields used in this evaluation were provided by NASA Johnson Space Center. The plain shield failed when struck by a $2.4-\mathrm{mm}$-diameter aluminum sphere traveling at $9.28 \mathrm{~km} / \mathrm{s}$. The damage produced on the rear wall was essentially identical to the damage shown for Shot No. 8-3288 in Fig. 3.

The damage pattern produced on the front and rear surface (inset) of the rear wall used for Shot No. 8-3225 is compared, in Fig. 6, to the damage pattern (front surface only) produced on the rear wall for Shot No. 8-3288. Shot Nos. 8-3225 and 8-3261 had a scaled sandwich of multilayer insulation (MLI) installed in the

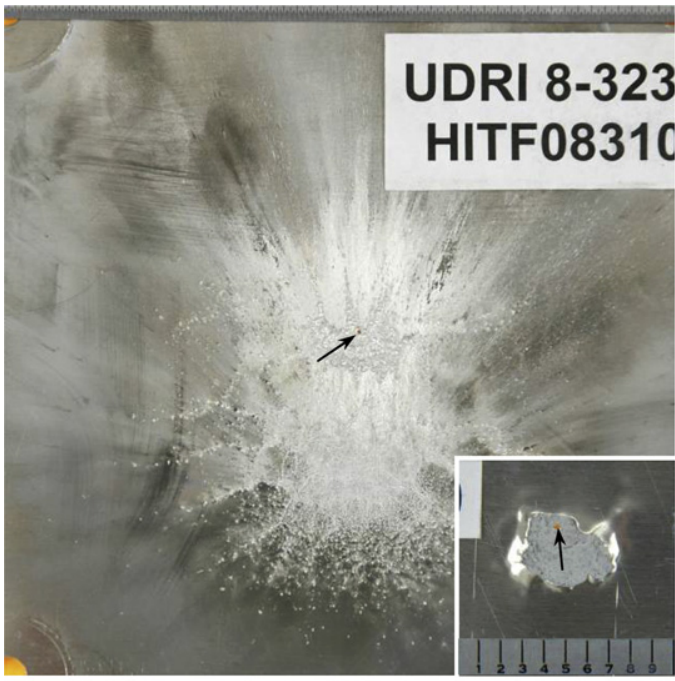

2.60-mm-dia., 2017-T4 Al sphere at $8.83 \mathrm{~km} / \mathrm{s}$ Shot No. 8-3239

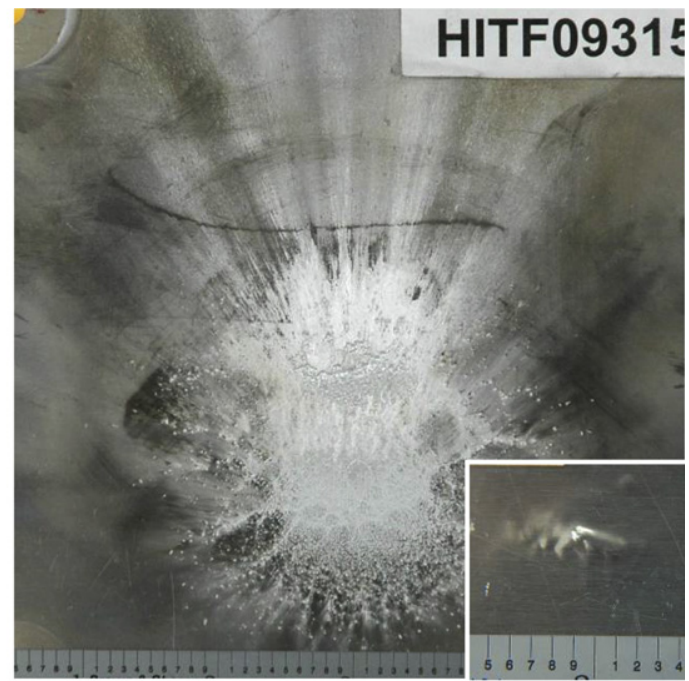

2.38-mm-dia., 2017-T4 Al sphere at $9.16 \mathrm{~km} / \mathrm{s}$ Shot No. 8-3264

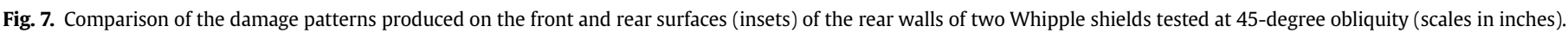




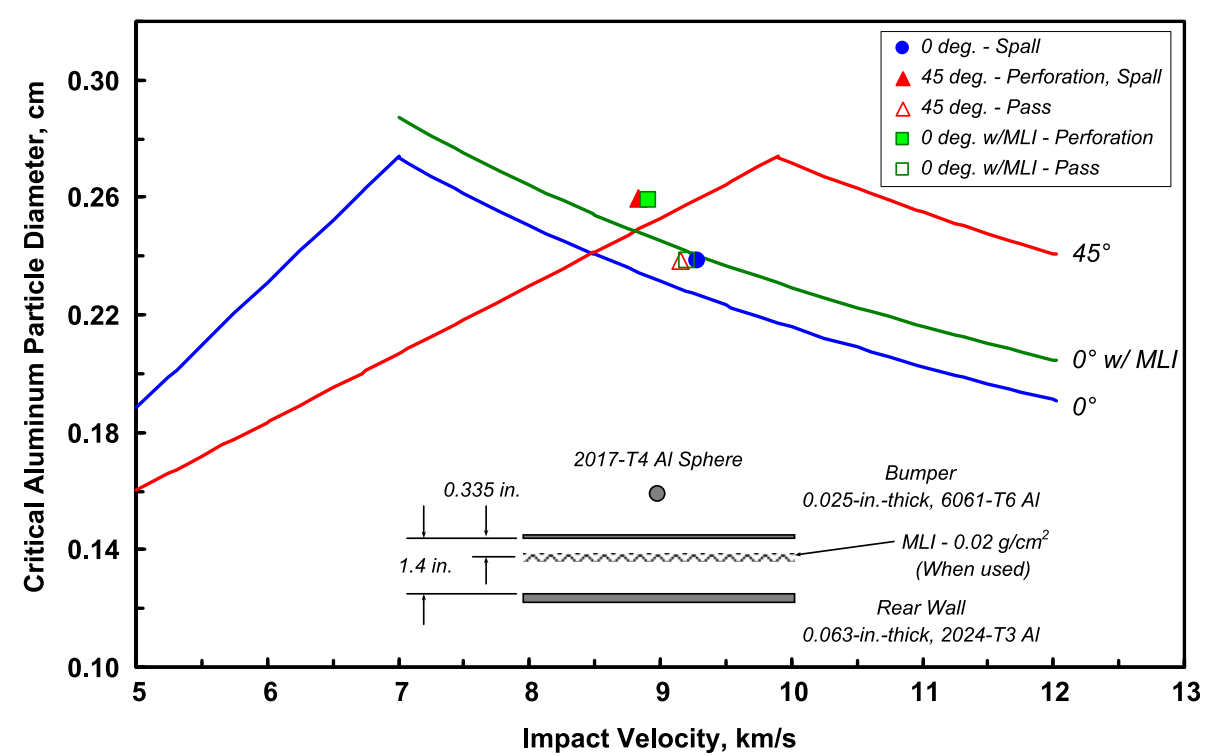

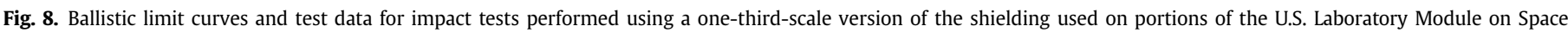
Station.

space between the bumpers and the rear walls of the shields. In both test firings, the MLI appeared to "funnel" the molten debris cloud toward the center of the rear wall, forming a jet of molten aluminum which perforated the rear wall for Shot No. 8-3225. The rear wall from Shot No. 8-3261 was not perforated but had two moderate-sized blisters at the center of its rear surface.

The damage patterns produced on the front and rear surfaces (insets) of the rear walls used for two tests in which the shields were mounted at 45-degree obliquity are compared in Fig. 7. The rear wall for Shot No. 8-3239 has a large spall and a $0.75-\mathrm{mm}$ diameter perforation (arrow). The rear wall for Shot No. 8-3264 has a large, irregularly shaped blister on it rear surface. The spall/ perforation failure and the spall blister were formed at a location on the rear wall which was just below the shot-line axis.

The ballistic limit curves for the plain shields shown in Fig. 8 were generated using the appropriate shield dimensions and material property data in Eqs. (2) and (3) for the 0- and 45-degree conditions. The ballistic limit curve for the shield with MLI was determined by adding the increment, $\Delta_{\mathrm{MLI}}$, to the critical particle diameter determined for the plain shield using Eq. (3). The increment $\Delta_{\mathrm{MLI}}$, in cm, is given by Christiansen [6] as follows:

$\Delta_{\mathrm{MLI}}=k_{\mathrm{MLI}} m_{\mathrm{MLI}}\left(S_{\mathrm{MLI}} / S\right)^{1 / 2}$

where $k_{\mathrm{MLI}}=1.4 \mathrm{~cm}^{3} / \mathrm{g}, m_{\mathrm{MLI}}$ is the areal density of the MLI in $\mathrm{g} / \mathrm{cm}^{2}$, and $S_{\mathrm{MLI}}$ is the distance from the bumper to the MLI. As shown in Fig. 8, the test results for the various shields indicated the ballistic limit curves adequately predicted the shield responses for impacts occurring near $9 \mathrm{~km} / \mathrm{s}$. Data from lower velocity tests should be included in Fig. 8 to determine whether dashed lines similar to those shown in Fig. 5 could be applicable for these shields.

\section{Summary and recommendations}

The work described in this paper evaluates the adequacy of the "new" modified Cour-Palais or Christiansen ballistic limit equation to predict the response of a simple, all-aluminum Whipple shield to the impact of an aluminum sphere when the impact velocity is high enough to produce melting and incipient vaporization of the sphere and bumper. The results of 13 test firings used in the evaluation of the performance of a simple Whipple shield showed that this shield offered better-than-predicted capability as impact velocity was increased and that the rear wall material properties appeared to only have a small effect on shield performance.

Three configurations of a one-third-scale version of shielding used on the U.S. Laboratory Module of Space Station shield were also evaluated. The shields used for these tests, one plain shield at 0 degrees, two shields (also at 0 degrees) with multilayer insulation in the space between the bumper and the rear wall, and two tests with the plain shield at 45 degrees obliquity, all met their predicted capabilities.

Use of the UDRI three-stage, light-gas gun to launch millimetersized aluminum spheres to velocities as high as $9.89 \mathrm{~km} / \mathrm{s}$ has significantly expanded the range of test velocities available for the impact testing of spacecraft structures and materials using projectiles with controlled properties. The impact velocities which have been achieved to date are slightly higher than the predicted mean and median impact velocities typical of the on-orbit environment of Space Station.

Impact testing of the simple, all-aluminum Whipple shield should continue, using aluminum spheres, to provide a more definitive description of its ballistic limit for normal and oblique impact angles. In addition, future testing should be performed, using simple, non-spherical projectiles, to provide additional data which would be used to construct a solid framework for describing the response of the simple shield to impacts of other shapes of projectiles at extremely high velocities. Inclusion of this framework in the interpretation of test results for more realistic or actual shield systems should be invaluable during evaluations of the response of the spacecraft components to potential threats.

\section{Acknowledgements}

A major portion of this work was supported by NASA Johnson Space Center under Grant NNX08AI04A. The authors wish to gratefully acknowledge the additional support provided by the Office of the Director of the University of Dayton Research Institute during further development of the UDRI three-stage, light-gas gun. The authors would also like to express their appreciation to the following UDRI associates: Tim Klopfenstein, for his meticulous and ever-present good attitude while fabricating all of the range and test hardware 
consumed during each test firing; and Kevin Fedon and Mark Collins for their cheerful assistance during the performance of the test firings.

\section{References}

[1] Whipple FL. Meteorites and space travel. Astronom J February 1947;1161(132).

[2] Hayashida KB, Robinson JH. Double-plate penetration equations. NASA-TM2000-209907. NASA; February 2000.
[3] Christiansen EL. Design and performance equations for advanced meteoroid and debris shields. Int J Impact Eng 1993;14:145-56.

[4] Piekutowski AJ, Poormon KL. Development of a three-stage, light-gas gun at the University of Dayton Research Institute. Int J Impact Eng 2006;33 :615-24.

[5] Piekutowski AJ. Formation and description of debris clouds produced by hypervelocity impact NASA CR 4707. NASA; February 1996.

[6] Christiansen EL. Meteoroid/debris shielding. NASA . NASA CR 4707. TP-2003210788. NASA; August 2003. 